\title{
Piezo- and Magnetoelectric Polymers as Biomaterials for Novel Tissue Engineering Strategies
}

\author{
C. Ribeiro ${ }^{\mathrm{a}, \mathrm{b}}$, D.M. Correia ${ }^{\mathrm{c}, \mathrm{d}}$, S. Ribeiro ${ }^{\mathrm{a}, \mathrm{e}}$, M. M. Fernandes ${ }^{\mathrm{a}, \mathrm{b}}$ and S. Lanceros-Mendez ${ }^{\mathrm{d}, \mathrm{f}^{*}}$ \\ ${ }^{a}$ Centro de Física, Universidade do Minho, Campus de Gualtar, 4710-058 Braga, Portugal \\ ${ }^{b}$ CEB - Centre of Biological Engineering, University of Minho, Campus de Gualtar, 4710-057 Braga, \\ Portugal \\ ${ }^{c}$ Department of chemistry and CQ-VR, University of Trás-os-Montes e Alto Douro, 5000-801 Vila Real, \\ Portugal \\ ${ }^{d}$ BCMaterials, Parque Científico y Tecnológico de Bizkaia, 48160 Derio, Spain \\ $e$ Centre of Molecular and Environmental Biology (CBMA), Universidade do Minho, Campus de Gualtar, \\ 4710-057 Braga, Portugal \\ ${ }^{f}$ IKERBASQUE, Basque Foundation for Science, 48013 Bilbao, Spain
}

corresponding author: senentxu.lanceros@bcmaterials.net

\section{ABSTRACT}

Tissue engineering and regenerative medicine are increasingly taking advantage of active materials, allowing to provide specific clues to the cells. In particular, the use of electroactive polymers that deliver an electrical signal to the cells upon mechanical solicitation, open new scientific and technological opportunities, as they in fact mimic signals and effects that occur in living tissues, allowing the development of suitable microenvironments for tissue regeneration. Thus, a novel overall strategy for bone and muscle tissue engineering was developed based on the fact that these cells type are subjected to mechano-electrical stimuli in their in vivo microenvironment and that piezo- and magnetoelectric polymers, used as scaffolds, are suitable for delivering those cues. The processing and functional characterizations of piezoelectric and magnetoelectric polymers based on poly(vinylindene fluoride) and poly-L-lactic acid in a variety of shapes, from microspheres to electrospun mats and three dimensional scaffolds, are shown as well as their performance in the development of novel bone and muscle tissue engineering.

\section{INTRODUCTION}

Piezoelectric polymers have already shown strong potential for novel tissue engineering (TE) strategies, once they can account for the existence of piezoelectricity within some specific tissues, indicating their requirement also during tissue regeneration [1]. Further, they can modulate the electrical signals existing during tissue development and function. Still, in some cases, the patient is immobilized, and as a result the natural mechanical stimulus does not occur [2]. Such limitation points to the 
development of new materials able to remotely mechanical and/or electrically stimulate tissues from outside of the human body and/or during in vitro cell culture to explore specific differentiation paths. Magnetoelectric (ME) composite materials provide such an innovative tool, allowing the use of an external magnetic field to remotely control tissue stimulation, without the need of patient movement. Those composites are composed of magnetostrictive and piezoelectric materials, resulting in the ME effect [3].

Moreover, for TE, the design of the scaffolds influence the transmission of biochemical, morphological, electrical and mechanical signals defining the ultimate shape of the newly grown soft or hard tissue [1].

In this way, new paradigms for TE also include the need of active/smart biomaterials with appropriate forms and geometries in order to properly regenerate specific tissues. The electromechanical stimulation can be effectively conducted by piezoelectric polymers, such as poly(vinylidene fluoride) (PVDF), a semi-crystalline polymer that has four differentiated crystalline phases $(\alpha, \beta, \gamma, \delta)$, being the $\beta$-phase the one with the highest piezoelectric coefficient [1]. However, PVDF polymer is nondegradable, and for approaches where biodegradability is required, poly(L-lactic acid) (PLLA), with lower piezoelectric response, can be employed.

\section{PIEZO- AND MAGNETOELECTRIC BIOMATERIALS AND STRUCTURES}

Electroactive polymers such as PVDF and PLLA have been processed into scaffolds with various morphologies and dimensionalities, including microspheres [4-5], membranes [6-8], fibers [9-11], and three dimensional (3D) scaffolds by different methods [12] such as electrospray, solvent casting and electrospinning methods (figure 1). Recently, efforts are being focus in the development of magnetoelectric biomaterials through the incorporation of magnetic particles for TE [13]. Scaffolds based on microspheres have received increasing attention for biomedical applications and support for cell expansion and differentiation [4, 14]. Piezo- and magnetoelectric microspheres can be produced by different methods such as phase separation or precipitation, emulsion/solvent evaporation and electrospray [4]. The variation of the processing parameters generally allows the control of the particle size and size distribution. PVDF microspheres with a smooth surface and an average diameter between $800 \mathrm{~nm}$ up to $7 \mu \mathrm{m}$ have been obtained by electrospray method, where microspheres are produced using a polymer solution in a sufficiently conductive solvent $[4,15]$. During the electrospray method, depending on the solution parameters (including solution concentration, viscosity and surface tension) and the processing parameters (flow rate, needle diameter, distance of needle to collector, and applied voltage), a continuous and charged jet can be broken down into droplets, resulting in microspheres of different size [16]. This method may overcome the drawbacks associated with conventional particle-producing methods such as solvent casting, single and double emulsion, spray-drying, porous glass membrane emulsification, and coacervation [16]. Few studies have been reported on PVDF and PLLA magnetoelectric microspheres. Magnetoelectric PVDF microspheres obtained by this method embedded magnetostrictive particles such as cobalt ferrites $\left(\mathrm{CoFe}_{2} \mathrm{O}_{4}\right)$ nanoparticles into the PVDF sphere matrix are mainly in the $\beta$-phase (between $65 \%$ and $85 \%$ ) [15]. It is worth noticing that electrospray does not allow an accurate control of the sphere size [17]. From an emulsion-solvent extraction/evaporation method it is possible obtain biodegradable piezo- and $\mathrm{CoFe}_{2} \mathrm{O}_{4}$ composite PLLA-based microspheres with controllable size and diameters ranging between 0.16 and $3.9 \mu \mathrm{m}$ for neat PLLA and between 0.8 and $2.2 \mu \mathrm{m}$ for the composite microspheres [17]. Particularly for neural and 
muscle applications, TE fibrous scaffolds have been designed to support and guide the longitudinal cells extension along their natural axis of growth [18]. Oriented and random electrospun fibers with small pore size, density and high surface area can be obtained by electrospinning, similarly to the electrospray method, when solution viscosity is high enough (in the range of $650-2500 \mathrm{cP}$ ) [19]. The electrospinning process allows to effectively obtain PVDF and PLLA random and oriented fibers using a static and a rotating collector, respectively, with average diameters ranging from $\sim 500-900 \mathrm{~nm}[11,20]$. According to [11], PVDF random electrospun fibers show a $\beta$ phase content around $50 \%$. Increasing the rotation speed of the collector from 500 to $2000 \mathrm{rpm}$, the fraction of $\beta$ phase increases and may range between 50 to $85 \%$ due to the higher stretching of the jet during the electrospinning process. Furthermore, the introduction of magnetostrictive nanoparticles into the polymeric PVDF solution allows the processing of

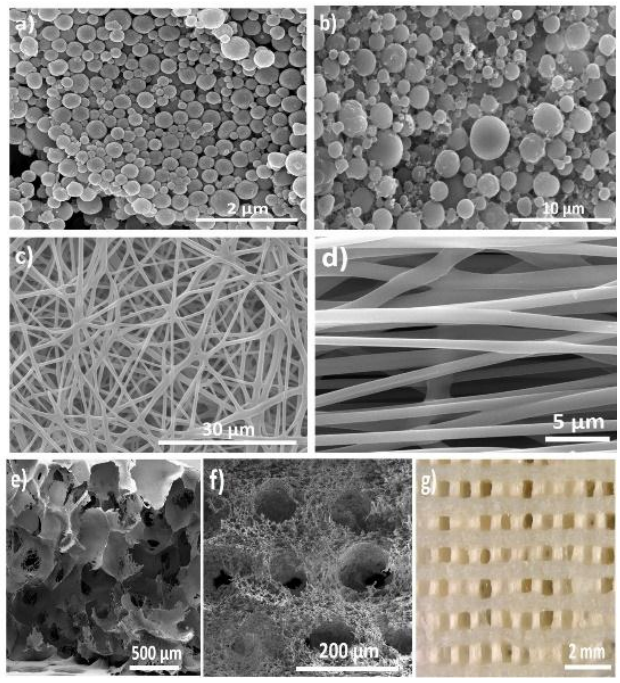

Figure 1. a)Neat and b) magnetic PLLA microspheres obtained by an oil-in-water emulsion; c) random and d) oriented PLLA fibers obtained by electrospinning; PVDF 3D scaffolds obtained by e)solvent casting/NaCl particulate leaching, f) solvent casting and nylon template and g) freeze extraction.

magnetoelectric fibers with an average fiber diameter of $\sim 325 \mathrm{~nm}$ [21]. According to [22], depending on solvent and electrospun processing parameters, it is possible to adjust the dominant crystalline phase producing fibers mainly containing $\alpha$ or trans-state ( $\beta$ or $\gamma$ phases). The crystallization process of PVDF predominantly in the $\beta$ phase can be obtained using high voltage or high stretching ratio of the jets and a rotating collector. Further, the processing conditions and solvent used influence the crystalline fraction and other characteristics such as fiber average diameter, specific surface area, surface tension and mechanical properties $[11,22]$.

Three dimensional porous scaffolds have been obtained by solvent casting/salt leaching, phase separation, gas foaming, gel casting, precipitation and emulsion freezedrying [12]. The main advantages of these pore interconnected scaffolds are related with their ability to promote better interaction between cells and tissues, transport of metabolite and nutrients and an appropriate transmission of biochemical/mechanical and or electrical cues leading to the stimulation of both cells and tissues [12]. Electroactive $\beta$ PVDF 3D scaffolds with different porous sizes, architectures and pore interconnectivity have been obtained by solvent casting/particulate leaching (300 to $400 \mu \mathrm{m})$ and using a nylon template $(\sim 60 \mu \mathrm{m}$ or $\sim 150 \mu \mathrm{m})$. Also, freeze extraction methods with a PVA template promotes the formation of porous scaffolds with averages diameters of $\sim 300$ and $500 \mu \mathrm{m}$, being the porous average diameters in the same range of the sacrificial material. Thus, the variation of the ratio of the salt into the solution and the distance of the filaments of the template allow to control the pore size of the scaffold [12]. A similar procedure, including liquid-liquid phase separation with freeze extraction is employed to process PLLA scaffolds with interconnected pores with pore size ranging from 20 to $60 \mu \mathrm{m}[23]$. 


\section{TISSUE ENGINEERING BASED ON PIEZO- AND MAGNETOELECTRIC BIOMATERIALS}

Active polymers have been used in several TE applications such as bone, neural and muscle tissues [24]. In particular, piezoelectric and magnetoelectric polymers have been used in different morphologies and with different cell type. However, most of these studies were performed in static conditions. The piezoelectric and magnetoelectric effect is only proven when the dynamic conditions (either mechanical or electrical) are applied (Table 1), otherwise, just the suitability of the materials and the significance of the surface charge, when the material is poled, are demonstrated [1].

PVDF and its copolymers are the piezoelectric polymer most used for TE applications due to their larger piezoelectric response [19]. In particular, most of the studies describing cell response under dynamic stimulation use PVDF as a support for the cell proliferation and differentiation. Rodrigues et al. showed that $\beta$-PVDF positively charged films provide an adequate environment for enhancing the growth and differentiation of goat marrow cells into osteoblast in dynamic conditions, exhibiting an ideal support for the seeding and the development of undifferentiated cells towards a desired phenotype [25]. The combination of biochemical and physical stimuli can lead to a successful approach of a biomimetic microenvironment present in the human body. Ribeiro et al. showed that PVDF negatively charged films [26] under dynamic conditions, more properly mechanical stimulation, lead to enhanced osteogenic differentiation of human adipose stem cells, which was confirmed by higher alkaline phosphatase activity [27]. In the presence of PVDF films, MC3T3-E1 pre-osteoblast cells showed different responses. In the presence of positively charged $\beta$-PVDF films and in mechanical stimuli, a higher osteoblast adhesion and proliferation was observed [28]. These results were confirmed with in vivo studies where $\beta$-PVDF films were implanted in a bone defect, demonstrating significantly more defect closure and bone remodeling. In this case, the mechanical solicitations are obtained by the rat movements [29]. Other piezoelectric polymers have also been used such as collagen type I where the studies demonstrated that the 3D samples mechanically stretched promote the proliferation and differentiation of human osteoblastic precursor cells due to the increase of genes expression related to the early and late stages of osteoblastic differentiation [30].

Relatively to nerve regeneration, it has also been shown that PVDF and poly(vinylidene fluoride-trifluoroethylene) (PVDF-TrFe) under dynamic conditions promote cell proliferation and differentiation. Previous studies reported by [31] demonstrated that poled PVDF increases the percentage of differentiated neurons of mouse neuroblastoma cells and respective neurite lengths after $96 \mathrm{~h}$ of cell culture with both media conditions. These results have been also verified with PVDF-TrFe [31]. Composites are also used. Thus, nerve stem cells cultured on PLLA nanofibers with PANI resulted in an extended neurite outgrowth when electrically stimulated when compared to the cells grown on non-stimulated scaffolds [18].

Guo et al. reported that polyurethane/poly(vinylidene fluoride) (PU/PVDF) prepared by electrospinning have an influence on wound healing. When the cells were excited by piezoelectric effect, the adhesion of the fibroblasts (NIH3T3) was enhanced and consequently, higher mRNA and protein expression levels than the control scaffolds were shown [32].

A novel approach for TE applications has been achieved with biomaterials with magnetoelectric response. The studies were realized with MC3T3-E1 pre-osteoblast cells and magnetoelectric Terfenol-D/PVDF-TrFe composites. These biomaterials promote $\approx 25 \%$ of cell proliferation when the cells are cultured under mechanical and electrical stimulation remotely triggered by the application of a varying magnetic field [17]. 
For muscle regeneration, it was already proven that the surface charged enhanced the cell proliferation [33]. However, until now, the study under dynamic conditions with piezoelectric biomaterials has not yet been performed.

Table 1 - Biomaterial, cell culture condition and cells used for different applications.

\begin{tabular}{|c|c|c|c|c|}
\hline Biomaterial & Conditions & Cells & Application & Ref. \\
\hline \multirow[b]{2}{*}{$\begin{array}{l}\text { PVDF } \\
\text { positively } \\
\text { poled }\end{array}$} & -Mechanical stimulation & Goat marrow & \multirow{5}{*}{ Bone } & [25] \\
\hline & $\begin{array}{l}\text {-Mechanical stimulation in vertical vibration } \\
\text {-Frequency }=1 \mathrm{~Hz} \\
\text {-Amplitude } \approx 1 \mathrm{~mm}\end{array}$ & $\begin{array}{c}\text { MC3T3-E1 } \\
\text { pre-osteoblast }\end{array}$ & & [28] \\
\hline $\begin{array}{l}\text { PVDF } \\
\text { negatively } \\
\text { poled }\end{array}$ & $\begin{array}{l}\text {-Mechanical stimulation in vertical vibration } \\
\text {-Frequency }=1 \mathrm{~Hz} \\
\text {-Maximum amplitude } \approx 1 \mathrm{~mm}\end{array}$ & $\begin{array}{c}\text { Human } \\
\text { adipose stem }\end{array}$ & & [27] \\
\hline $\begin{array}{l}\text { Terfenol- } \\
\text { D/P(VDF- } \\
\text { TrFE) }\end{array}$ & $\begin{array}{l}\text {-Magnetic stimulation; } \\
\text {-Active time }=16 \mathrm{~h}(10 \mathrm{~min} \text { of active time and } \\
20 \text { min of repose time } ; \\
\text {-Non-active time }=8 \mathrm{~h} ; \\
\text {-Frequency }=0.3 \mathrm{~Hz} ; \\
\text {-Displacement of permanent magnets } \approx 20 \mathrm{~mm} \text {; } \\
\text {-Maximum value }=230 \mathrm{Oe} ; \\
\text {-ME voltages }=0.115 \mathrm{mV} \text {. }\end{array}$ & $\begin{array}{c}\text { MC3T3-E1 } \\
\text { pre-osteoblast }\end{array}$ & & [17] \\
\hline Colagen type I & $\begin{array}{l}\text {-Stretched cyclically along the long axis } \\
\text {-Frequency }=1 \mathrm{~Hz} \\
\text {-Magnitude }=10,000 \mu \text { strain }(1 \%) \\
\text {-Number of cycles }=1800 \\
\text {-Time = every day for } 30 \text { min over a period of } 3 \\
\text { weeks. }\end{array}$ & $\begin{array}{l}\text { Human } \\
\text { osteoblastic } \\
\text { precursor }\end{array}$ & & [30] \\
\hline $\begin{array}{l}\text { PVDF and } \\
\text { PVDF-TrFe }\end{array}$ & $\begin{array}{l}\text {-Sinusoidal output (vibrational forces); } \\
\text {-Peak voltage } \approx 2.5 \mathrm{mV} \\
\text {-Frequency }=1200 \mathrm{~Hz} \\
\text {-Standard incubator shelves }\end{array}$ & $\begin{array}{c}\text { Mouse } \\
\text { neuroblastoma }\end{array}$ & & [31] \\
\hline PLLA/PANI & $\begin{array}{l}\text {-A silver electrode and a platinum electrode were } \\
\text { inserted to opposite ends of the nanofibrous } \\
\text { scaffold; } \\
\text {-Constant voltage }=1.5 \mathrm{~V} ; \\
\text {-Time }=60 \mathrm{~min} ; \\
\text {-Electric field }=100 \mathrm{mV} / \mathrm{mm} \text {. }\end{array}$ & $\begin{array}{c}\text { Nerve stem } \\
\text { cells }\end{array}$ & Nerve & [18] \\
\hline PU/PVDF & $\begin{array}{l}\text {-Intermittent deformation of } 8 \% \\
\text {-Frequency }=0,5 \mathrm{~Hz}\end{array}$ & NIH3T3 & $\begin{array}{l}\text { Wound } \\
\text { healing }\end{array}$ & [32] \\
\hline
\end{tabular}

\section{CONCLUSIONS}

The abovementioned studies indicate the relevance of the use of piezo- and magnetoelectric biomaterials for tissue engineering applications, allowing the development of a novel biomimetic approach, where electrical and/or electromechanical stimuli is required for proper cell/tissue development.

\section{ACKNOWLEDGEMENTS}

The authors thank the Portuguese Fundação para a Ciência e Tecnologia (FCT) for financial support under Strategic Funding UID/FIS/04650/2013 and project PTDC/EEI-SII/5582/2014, including FEDER funds, UE. The authors also thank the FCT for financial support under grants SFRH/BPD/90870/2012 (CR), SFRH/BPD/121526/2016 (DMC), SFRH/BD/111478/2015 (SR) and SFRH/BPD/121464/2016 (MMF). Financial support from the Spanish Ministry of Economy and Competitiveness (MINECO) through the project MAT2016-76039-C4-3-R 
(AEI/FEDER, UE) (including the FEDER financial support) and from the Basque Government Industry Department under the ELKARTEK Program is also acknowledged.

\section{References:}

1. C. Ribeiro, V. Sencadas, D. M. Correia and S. Lanceros-Méndez, Colloids Surf B 136, $46-55$ (2015).

2. M. Mehta, K. Schmidt-Bleek, G. N. Duda and D. J. Mooney, Adv Drug Deliv Rev 64 (12), 12571276 (2012).

3. P. Martins and S. Lanceros-Méndez, Adva Funct Mater 23 (27), 3371-3385 (2013).

4. D. M. Correia, R. Golcalves, C. Ribeiro, V. Sencadas, G. L. Botelho, J. L. Gomez-Ribelles and s. lanceros-mendez, RSC Adv 4 , 33013-33021 (2014).

5. D. M. Correia, V. Sencadas, C. Ribeiro, P. M. Martins, P. Martins, F. M. Gama, G. Botelho and S. Lanceros-Méndez, J Colloid Interf Sci 476, 79-86 (2016).

6. V. Sencadas, R. Gregorio and S. Lanceros-Méndez, J Macromolec Sci B 48 (3), 514-525 (2009).

7. S. J. Hong, H. S. Yu and H. W. Kim, Acta Biomaterialia 5 (5), 1725-1731 (2009).

8. V. Sencadas, S. Lanceros-Méndez and J. F. Mano, Thermochimica Acta 424 (1-2), 201-207 (2004).

9. Z. H. Liu, C. T. Pan, L. W. Lin and H. W. Lai, Sens Actuat A 193 (0), 13-24 (2013).

10. H. Na, X. Liu, J. Li, Y. Zhao, C. Zhao and X. Yuan, Polymer 50 (26), 6340-6349 (2009).

11. C. Ribeiro, V. Sencadas, J. L. G. Ribelles and S. Lanceros-Méndez, Soft Mater 8 (3), 274-287 (2010). 12. D. M. Correia, C. Ribeiro, V. Sencadas, L. Vikingsson, M. Oliver Gasch, J. L. Gómez Ribelles, G. Botelho and S. Lanceros-Méndez, Mater Design 92, 674-681 (2016).

13. C. Ribeiro, V. Correia, P. Martins, F. M. Gama and S. Lanceros-Mendez, Colloids Surf B 140, 430436 (2016).

14. M. N. T.-M. R. Sobreiro-Almeida, E. O. Carvalho, L. Cordón, S. Doria, L. Senent, D. M. Correia, C. Ribeiro, S. Lanceros-Méndez, R. Sabater i Serra, J. L. Gomez Ribelles and A. Sempere, Intern J Molec Sci 18 (11), 2391 (2017).

15. R. Gonçalves, P. Martins, D. M. Correia, V. Sencadas, J. L. Vilas, L. M. León, G. Botelho and S. Lanceros-Méndez, RSC Adv 5 (45), 35852-35857 (2015).

16. M. Zamani, M. P. Prabhakaran and S. Ramakrishna, Int J Nanomedicine 8, 2997-3017 (2013).

17. D. M. Correia, V. Sencadas, C. Ribeiro, P. M. Martins, P. Martins, F. M. Gama, G. Botelho and S. Lanceros-Méndez, J Colloid Interf Sci 476 (Supplement C), 79-86 (2016).

18. M. P. Prabhakaran, L. Ghasemi-Mobarakeh, G. R. Jin and S. Ramakrishna, J. Biosci. Bioeng. 112 (5), 501-507 (2011).

19. C. Ribeiro, D. M. Correia, S. Ribeiro, V. Sencadas, G. Botelho and S. Lanceros-Méndez, Eng Life Sci 15 (4), 351-356 (2015).

20. C. Ribeiro, V. Sencadas, C. M. Costa, J. L. Gómez Ribelles and S. Lanceros-Méndez, Sci Technol Adv Mater 12 (1) (2011).

21. R. Gonçalves, P. Martins, X. Moya, M. Ghidini, V. Sencadas, G. Botelho, N. D. Mathur and S. Lanceros-Mendez, Nanoscale 7 (17), 8058-8061 (2015).

22. J. Zheng, A. He, J. Li and C. C. Han, Macromolecular Rapid Commun 28 (22), 2159-2162 (2007).

23. L. Budyanto, Y. Q. Goh and C. P. Ooi, J Mater Sci: Mater Medicine 20 (1), 105-111 (2009).

24. A. H. Rajabi, M. Jaffe and T. L. Arinzeh, Acta Biomater. 24, 12-23 (2015).

25. M. T. Rodrigues, M. E. Gomes, J. F. Mano and R. L. Reis, in Advanced Materials Forum Iv, edited by A. T. Marques, A. F. Silva, A. P. M. Baptista, C. Sa, F. Alves, L. F. Malheiros and M. Vieira (Trans Tech Publications Ltd, Stafa-Zurich, 2008), Vol. 587-588, pp. 72-76.

26. J. Parssinen, H. Hammaren, R. Rahikainen, V. Sencadas, C. Ribeiro, S. Vanhatupa, S. Miettinen, S. Lanceros-Mendez and V. P. Hytonen, J. Biomed. Mater. Res. A 103 (3), 919-928 (2015).

27. C. Ribeiro, J. Parssinen, V. Sencadas, V. Correia, S. Miettinen, V. P. Hytonen and S. LancerosMendez, J. Biomed. Mater. Res. A 103 (6), 2172-2175 (2015).

28. C. Ribeiro, S. Moreira, V. Correia, V. Sencadas, J. G. Rocha, F. M. Gama, J. L. G. Ribelles and S. Lanceros-Mendez, RSC Adv. 2 (30), 11504-11509 (2012).

29. C. Ribeiro, D. M. Correia, I. Rodrigues, L. Guardao, S. Guimaraes, R. Soares and S. LancerosMendez, Mater Letters 209, 118-121 (2017).

30. A. Ignatius, H. Blessing, A. Liedert, C. Schmidt, C. Neidlinger-Wilke, D. Kaspar, B. Friemert and L. Claes, Biomaterials 26 (3), 311-318 (2005).

31. R. F. Valentini, T. G. Vargo, J. A. Gardella and P. Aebischer, Biomaterials 13 (3), 183-190 (1992).

32. H. F. Guo, Z. S. Li, S. W. Dong, W. J. Chen, L. Deng, Y. F. Wang and D. J. Ying, Colloids Surf B 96, 29-36 (2012).

33. P. M. Martins, S. Ribeiro, C. Ribeiro, V. Sencadas, A. C. Gomes, F. M. Gama and S. LancerosMéndez, RSC Adv 3 (39), 17938-17944 (2013). 